\title{
The Effects of Auditory Feedback from the Nucleus Cochlear Implant on the Vowel Formant Frequencies Produced by Children and Adults
}

\author{
Louise M. Richardson, Peter A. Busby, Peter J. Blamey, Richard C. Dowell, and Graeme M. Clark
}

\begin{abstract}
Cochlear implants provide an auditory signal with which profoundly deaf users may monitor their own speech production. The vowel production of two adults and three children who used the Nucleus multiple-electrode cochlear implant was examined to assess the effect of altered auditory feedback. Productions of words were recorded under conditions where the talkers received auditory feedback (speech processor turned on) and where no auditory feedback was provided (speech processor turned off). Data were collected over 3 days at weekly intervals. First and second formant frequencies were measured and the data were analysed to assess significant differences between auditory feedback conditions, vowel context, and data collection points. Overall, the results varied across talkers, across the data collection days, and depended on the consonant environment of the vowel. However, two effects of auditory feedback were noted. First, there was a generalized shift in first formant frequencies between the processor on and processor off conditions across three of the five subjects, but the shift differed in direction for each subject. Second, for three of the five talkers, the two front vowels $/ \varepsilon /$ and $/ 1 /$ were more neutralised in the absence of auditory feedback. However, this effect was less pronounced than that noted by previous studies.
\end{abstract}

In a recent study, Svirsky and Tobey (1991) concluded that manipulation of auditory feedback in users of the Nucleus multichannel cochlear implant was a useful experimental protocol for examining the role of feedback in speech production. They investigated the changes in the first formant and second formant frequencies of vowels produced by two postlinguistically deafened adult subjects, with and without auditory feedback. Their data showed a tendency for the intermediate vowels to become more neutralised in the absence of auditory feedback.

Our study involved two main objectives. The first aim was to examine the effects of auditory feedback

Department of Otolaryngology, East Melbourne, Victoria, Australia. on the vowel production of a larger and more diversified sample of adults and children. The second aim was to determine the reliability of vowel production changes, with and without auditory feedback, using a repeated sequence of experiments over several data collection points for each talker.

Several factors complicate the analysis of the vowel production of hearing-impaired talkers. There is a tendency for the vowel production of hearing-impaired children to contain certain types of errors. These errors include nasalization, dipthongization, neutralization, substitution, and hoarseness (Angelocci, Kopp, \& Holbrook, 1964; Hudgins \& Numbers, 1942; Markides, 1970; Nober, 1967; Smith, 1975). As a consequence, the vowel production of deaf children tends to be less intelligible. Angelocci et al (1964) reported that only $32 \%$ of the vowels spoken by deaf children could be correctly identified by independent judges. Moreover, the speech of deaf talkers tends to be more variable than that of their hearing counterparts, as shown by Angelocci et al (1964). Also, children who incur deafness while they are still learning speech and language are disadvantaged in their acquisition of speech and language skills in comparison to individuals who lose their hearing after speech and language has developed. Therefore, we may expect speech production changes in prelinguistically deafened talkers to be quite different to those of postlinguistically deafened talkers.

The limited number of studies which have examined the speech production of children who use cochlear implants suggest a role for cochlear implants in monitoring speech production. Improvements in the speech production of pediatric cochlear implant users have been reported (Kirk \& Hill-Brown, 1985; Busby, Tong, Roberts et al, 1989; Tobey \& Hasenstab, 1991). Economou, Tartter, Chute, and Nellman (1992) reported neutralisation of the vowel space of one subject after failure of a $3 \mathrm{M} /$ House device and subsequent expansion of the vowel space one year after reimplantation with the Nucleus device. However, these studies have been more concerned with the longitudinal effects of cochlear implants on speech 
production and may involve a mechanism different from that influencing speech production changes during more short term auditory deprivation. Tobey, Angelette, Murchinson et al (1991) measured the effect of auditory stimulation provided by cochlear implants to children for monitoring and refining speech production on an ongoing basis. They measured the second formant frequencies of the word "head", with and without auditory feedback from the Nucleus prosthesis, in a sample of 13 children. They showed that mean F2 frequency values were lower in the absence of feedback. These findings were consistent with their hypothesis that auditory feedback provides a short term calibration function.

Although profoundly deaf children who receive cochlear implants are provided with improved access to auditory information, they must develop skills in using this information. It is not known to what extent these children are able to incorporate the new auditory input provided by the implant into existing strategies for the ongoing monitoring of their speech production. These children have probably developed alternative methods for controlling their speech in an open-loop fashion or based on feedback via other senses to accommodate for their hearing loss. In the case of congenitally deafened children, their experience with the use of feedback will have been limited to visual, tactual and social feedback. The child may have relied on proprioceptive feedback from conscious attention to articulator position and neural information about articulatory forces and speeds. Likewise, the child may have used somesthetic feedback from vibration or air pressure changes within the vocal tract and articulatory movements such as lip closure and tongue contact with various points of the vocal tract. In addition, the child may have been very reliant upon social feedback from educators or parents who indicate the acceptability of the child's speech production. Therefore, it is likely that the degree to which profoundly hearingimpaired talkers use auditory feedback from the cochlear implant to monitor their speech production will depend largely on their age at the onset of deafness and previous experience with the use of auditory feedback. Also, talkers with more experience using their implant may rely more heavily on auditory feedback provided by the implant.

In comparison, postlinguistic deafness does not cause marked deterioration in production and postlinguistically deaf talkers still remain quite intelligible. However, the deterioration of a number of production parameters has been documented (Cowie \& DouglasCowie, 1983; Fourcin, Rosen, Moore et al, 1979; Lane \& Wozniak Webster, 1991; Plant, 1983; Plant \& Hammarberg, 1983; Zimmermann \& Rettaliata, 1981).
It also seems that the auditory feedback provided by cochlear prostheses in adults may lead to changes and improvements in several aspects of speech production (Kirk and Edgerton, 1983; Lane, Perkell, Svirsky, \& Webster, 1991, Leder, Spitzer, Milner et al, 1986; Perkell, Lane, Svirsky, \& Webster, 1992; Plant \& Oster, 1986; Oster, 1986; Waters, 1986). In particular, Plant and Oster (1986) and Oster (1986) noted a generalised backwards shift of their subject's vowel space. Tartter, Chute, and Hellman (1989) noted a gradual shrinking and reduction of the vowel space postimplant in a postlinguistically deafened teenager. However, listener ratings indicated that this talker's postimplant speech production sounded better than in the preimplant recordings. This perceived improvement may have been due to better suprasegmental and consonant voicing production.

It is not yet clear whether these changes in speech production will be consistent for all multichannel cochlear implant users. There are three areas of this issue which require clarification. First, for postlinguistically deafened adults, cochlear implants restore a system which has been disrupted, while for young children, cochlear implants provide a mode of stimulation which is new or with which they have had little experience. Thus we may expect that the role of auditory feedback in the speech production of children may differ from its role for adult speakers. Our study examined changes in the vowel production of both adults and children under conditions where the talker received auditory feedback (speech processor turned on) and where there was no auditory feedback (speech processor turned off). Second, among the studies which have examined changes in vowel production postimplantation, there are differing results as demonstrated by the studies of Plant and Oster (1986), Tartter et al (1989), and Economou et al (1992). This may be partly due to the small number of subjects in these studies; each study had a sample size of one. We examined a larger sample of talkers. Third, the effect of auditory feedback on vowel formant frequencies may be affected by differences in the consonant context. We examined vowels produced in different contexts.. However, because it was necessary to choose words which were within the vocabulary of the children, it was not possible to vary the consonant context in a consistent manner across vowels.

\section{Methods}

\section{Subjects}

Two adults and three children with profound-tototal bilateral sensorineural hearing impairments were subjects for our study. Table 1 provides a summary 
Table 1. Summary of implant user histories

\begin{tabular}{|c|c|c|c|c|c|c|}
\hline Talker & $\begin{array}{l}\text { Age } \\
\text { (years) }\end{array}$ & Sex & $\begin{array}{c}\text { Age at confirmation } \\
\text { of profound hearing } \\
\text { loss (years) }\end{array}$ & $\begin{array}{l}\text { Etiology of deaf- } \\
\text { ness }\end{array}$ & $\begin{array}{l}\text { Length of cochlear } \\
\text { implant use } \\
\text { (years) }\end{array}$ & $\begin{array}{l}\text { Interval between } \\
\text { onset of deafness } \\
\text { and implantation } \\
\text { (years) }\end{array}$ \\
\hline$A 1$ & 69 & $M$ & 45 & $\begin{array}{l}\text { progressive and } \\
\text { acoustic trauma }\end{array}$ & 7.2 & 16.8 \\
\hline $\mathrm{A} 2$ & 69 & $F$ & 59 & $\begin{array}{l}\text { progressive and } \\
\text { ototoxic drugs }\end{array}$ & 3.8 & 6.2 \\
\hline $\mathrm{C} 1$ & 11 & $\mathrm{~F}$ & 0.5 & $\begin{array}{l}\text { congenital, un- } \\
\text { known cause }\end{array}$ & 3.4 & 7.6 \\
\hline $\mathrm{C} 2$ & 10 & $M$ & 3 & meningitis & 5.1 & 1.9 \\
\hline C3 & 7 & $M$ & 2 & meningitis & 3.8 & 1.2 \\
\hline
\end{tabular}

of their audiologic histories. The talkers were selected on the basis of having used their prostheses for a period of 12 months or more before the study, and they had volunteered to be involved in research. Talkers A1 and A2 suffered progressive hearing losses. For $\mathrm{A} 1$, a deteriorating hearing loss was first noticed at 31 years of age. The hearing of talker A2 began deteriorating at 24 years of age. For $\mathrm{C} 1$, a profound congenital hearing loss was diagnosed at 6 months of age and the etiology is unknown. The other two children, $\mathrm{C} 2$ and $\mathrm{C} 3$, became deafened after episodes of meningitis, and profound hearing impairment was confirmed within one month after recovery. All subjects were fitted with high-gain postauricular hearing aids after diagnosis of profound hearing loss. $\mathrm{C} 2$ and $\mathrm{C} 3$ were also fitted with a single-channel vibrotactile device (TACTAID-1). Use of these devices was discontinued after implantation.

$\mathrm{C} 1$ and $\mathrm{C} 3$ attended a school for the deaf that encouraged auditory-oral communication with cued speech as a supplement. Child C2 originally attended the same school but has now been mainstreamed into a regular school.

The most recent measures of each subject's speech perception were obtained from their clinical records. The scores for confusion studies using 11 vowels were 93.3 and $74.9 \%$, respectively, for $\mathrm{A} 1$ and $\mathrm{A} 2$, using the implant only. The children have not yet been tested using vowel confusion studies. An indication of their perceptual skills was obtained from the results for the Monosyllable-Spondee-Trochee-Polysyllable test and the Picture Vocabulary test (Plant, 1984). Identification scores for the M.S.T.P. test, using the implant only, were $83 \%, 100 \%$ and $77 \%$ for $\mathrm{C} 1, \mathrm{C} 2$ and $\mathrm{C} 3$ respectively. For the Monosyllable-Spondee-Trochee-Polysyllable test, children are required to identify words from a closed set of 12, consisting of 3 monosyllables ( $\mathrm{dog}$, car, fish), 3 trochees (table, rabbit, apple), 3 spondees (football, toothbrush, icecream) and 3 polysyllables (helicopter, butterfly, kangaroo). The chance score for identification is $8.3 \%$. For the Picture Vocabulary test, the scores were 58,100 , and $100 \%$ respectively for $\mathrm{C} 1, \mathrm{C} 2$, and $\mathrm{C} 3$. The Picture Vocabulary Test consists of 12 monosyllabic words: tree, fish, book, bird, shoe, duck, car, key, bed, dog, hat, and fork. These words include each of the 11 monophthongs in Australian English. The chance score for this test is also $8.3 \%$.

All talkers were implanted with the Nucleus multiple electrode prosthesis (Clark et al, 1987). For $\mathrm{A} 1, \mathrm{~A} 2, \mathrm{C} 1$, and $\mathrm{C} 3$, all 22 electrodes were inserted into the scala tympani. For $\mathrm{C} 2$, only 12 electrodes were successfully placed in the cochlea due to an obstruction in the scala.

The Nucleus MSP speech processor was used by each subject. A1, A2, C1, and C3 used the Multi-Peak speech coding scheme (Dowell, Whitford, Seligman et al, 1990; Skinner, Holden, Holder et al, 1991). In this scheme, first and second formant frequencies determine which electrodes are stimulated and three high-frequency band-pass signals are presented to three fixed electrodes in the basal region. The amplitudes are coded as stimulus levels, a combination of pulse width and current level. The stimulation rate is equal to the fundamental frequency for voiced sounds and a random rate varying around $260 \mathrm{~Hz}$ is used for unvoiced sounds. For C2, an alternative scheme was implemented due to the availability of only 7 electrodes for stimulation. Three of the most basal electrodes were excluded because they caused unpleasant sensations. This strategy involved the coding of the fundamental and the first and second formant frequencies as for the Multi-Peak scheme; and high frequency energy was coded on the most basal electrode.

\section{Test Material}

The speech tokens chosen for the study were a list of twenty-two monosyllabic words within the vocabulary of the children. These words, shown in Table 2, consisted of the eleven steady state vowels 
Table 2. Vowels and test words

\begin{tabular}{|c|c|c|}
\hline Vowel & \multicolumn{2}{|c|}{ Words containing vowel } \\
\hline /il & sheep $(1)^{a}$ & bees $(2)$ \\
\hline$|\varepsilon|$ & $\operatorname{peg}(1)$ & bed (2) \\
\hline /a/ & shark (1) & cart (2) \\
\hline$/ u /$ & boot (1) & tooth (2) \\
\hline $\mid \mathrm{j} /$ & fork (1) & cork (2) \\
\hline$/ 1 /$ & fish (1) & zip (2) \\
\hline$|æ|$ & $\operatorname{tap}(1)$ & $\operatorname{van}(2)$ \\
\hline$|n|$ & $\operatorname{cup}(1)$ & thumb (2) \\
\hline$/ v /$ & book (1) & foot (2) \\
\hline $\mid \mathrm{p} /$ & sock (1) & $\operatorname{dog}(2)$ \\
\hline$|3|$ & shirt (1) & bird (2) \\
\hline
\end{tabular}

"The numbers in brackets correspond to the subscripts used to denote the words in Figures 1a-1e.

of Australian English in a consonant-vowel-consonant context. There were two occurrences of each vowel in the list of words.

\section{Procedures}

The subjects' productions of the words were recorded on a TEAC tape recorder. A stand-mounted Marantz EC-2 microphone was positioned approximately 15 centimeters in front of the talker's mouth. All recordings were made in a quiet room with an ambient background sound level of less than $45 \mathrm{dBA}$. The adults attended the Department of Otolaryngology for testing. The children were tested in a room at the school that they attended.

In designing the experiment, we were interested in following the same procedure used by Svirsky and Tobey (1991), but it was necessary to make some changes in order to minimize inconvenience to the talkers. The adults required auditory input while they travelled to the test center. Thus they arrived at recording sessions with their speech processor turned on. Three recording conditions were used: speech processor on (labeled as $\mathrm{ON}$ ), immediately after the processor was turned off (labeled as OFF1), and twenty minutes after the processor had been turned off (labeled as OFF2). The order of conditions was reversed for the children so that their classroom activities would not be disrupted by requiring them to turn their speech processor off for long periods during the day. The children were instructed to switch their processor off and to leave it switched off the evening before each recording session until they attended the testing at the beginning of the next day. The conditions for the children were: processor switched off (labeled as OFF), processor on (labeled as ON1), and after the processor had been switched on for three hours (labeled as ON2). Each talker was requested to read the list of words three times, pausing between words, for each condition. For all talkers, these recording procedures were repeated over three data collection points, one week apart, to make a total of nine tokens for each word in each condition. In reversing the conditions, we did not necessarily expect to observe a symmetric reversal of the results. Previous studies found that changes in speech production were less pronounced when the speech processor was turned off compared to changes that occurred when the speech processor was turned on after 24 hours of non-use (Svirsky \& Tobey, 1991; Svirsky et al, 1992).

Spectrograms were prepared on a Kay Digital Sonograph (Model 7800) using a $300 \mathrm{~Hz}$ bandwidth filter for most analyses. The filter width was varied depending on the fundamental frequencies across the different talkers and speech samples. The vowel boundaries were determined using the criteria established by Peterson and Lehiste (1960). For words beginning with a voiceless plosive, the initial vowel boundary was determined by the onset of voicing after the aspiration.

In the case of voiced plosives, the initial vowel boundary was determined by the center of the releasing spike. Where the words ended with a voiced plosive, the end-point of the vowel was determined by the point where high-frequency energy suddenly diminished. For final voiceless plosives, the vowel boundary was determined by the sudden cessation of all formants. For words ending with a nasal, the sudden change in the comparative marking of the formant bands was used to judge the end-point of the vowel. For initial voiced fricatives, the vowel boundary was determined by the abrupt cessation of noise. For words beginning with a voiceless fricative, the onset of voicing in the region of the first formant determined the initial vowel boundary. The vowel boundaries for words ending with a voiced fricative were determined by the abrupt change in high frequency energy. For words ending with a voiceless fricative, the final vowel boundary was determined by the onset of noise. First and second formant frequency positions were measured by visual inspection of the graphical display of the average power spectra and spectrogram. Half of the speech samples were reanalyzed to obtain a measure of the reliability of the acoustic measurement. The root-mean-square error between the experimenter and the first judge was $38 \mathrm{~Hz}$ for the first formant data and $65 \mathrm{~Hz}$ for the second formant data.

The data from each subject was considered separately. Three-way analyses of variance (ANOVA) were performed to compare variance within session and over the 3 experimental days, and to make comparisons between the three experimental conditions. The independent variables were DAY, CON- 
DITION and WORD, and the first and second formant values were treated separately as the dependent variables. Post hoc analyses of the means were performed using the Newman-Keuls range test. A significance level of $p<0.01$ was used for all analyses.

It should be noted that a strong main effect is expected for WORD because of the phonetic differences in the vowels and the effect of consonant environment. A main effect for CONDITION would indicate a shift in the formant frequencies between the OFF and ON conditions. A tendency for the formant frequencies to centralize for some vowels, as observed by Svirsky and Tobey (1991), would give rise to a WORD by CONDITION interaction. A main effect for DAY or an interaction between DAY and other factors would indicate variable or inconsistent performance across data collection days.

\section{Results}

Figures 1a-1e show the vowel formant frequency data averaged over the three recording sessions for talkers $\mathrm{A} 1, \mathrm{~A} 2, \mathrm{C} 1, \mathrm{C} 2$, and $\mathrm{C} 3$, respectively. In all cases, the end point of the arrows indicate the mean formant frequency values when the device was turned off. For A1, the first formant frequencies were generally higher for the OFF1 and OFF2 conditions than for the ON condition, as indicated by the arrows in Figure 1a. For A2, changes across conditions were more marked for the front and low vowels, which were centralised for the OFF1 condition. In particular, first formant values for the low vowels were lower for the OFF1 condition than for the ON condition. The data for $\mathrm{C} 1$ indicated that this child had a distorted and neutralised vowel space. The shifts in the formant frequency values between speaking conditions did not show any particular pattern of movement. The vowel space for $\mathrm{C} 2$ was not as neutralised as for $\mathrm{C} 1$. However, the data in Figure $1 \mathrm{~d}$ indicated that for $\mathrm{C} 2$ there were minor changes in the formant frequency values between speaking conditions. The vowel space for $\mathrm{C} 3$ also was not as neutralised as for $\mathrm{C} 1$. For $\mathrm{C} 3$, shifts in the formant frequency values were not in a uniform direction except for some of the front vowels, which were more neutralised in the OFF position (Figure 1e).

The results of the ANOVA analysis are shown in Table 3. The data for the two contexts of each vowel were different from each other. Therefore, it was necessary to analyse the data in terms of the words spoken rather than averaging the values from the pairs of words containing the same vowel.

There was a significant main effect for WORD for all talkers for both the first formant and second formant data, as shown in Table 3. This confirmed that, as expected, the means of the formant frequencies differed among the words.

For three talkers (A1, C1, and $\mathrm{C} 3$ ), the means for the first formant frequencies differed between auditory feedback conditions, confirmed by a main effect for CONDITION. However, significant CONDITION by WORD effects indicated that the difference in conditions varied depending on the word spoken. For A1, the post hoc test showed that the CONDITION effect was significant across the majority of words (Table 4a), one word for $\mathrm{C} 1$ and five words for C3 (Table 4b). Although talkers A2 and C2 showed no main CONDITION effect, a significant CONDITION by WORD effect was observed for these two talkers. For A2, significant differences occurred between the conditions for one word (Table 4a) while for $\mathrm{C} 2$, significant differences were found between the conditions for two words (Table $4 \mathrm{~b}$ ).

The ANOVA results for the second formant frequencies showed a significant main effect for CONDITION for A2 only. A significant CONDITION by WORD effect for this talker revealed significant differences between the speaking conditions of three words (Table 4a). Significant CONDITION by WORD effects occurred for talkers A1, C2, and C3. Post hoc analyses showed significant differences between conditions for one word for A1 (Table 4a) and C2 (Table 4b) and 3 words for C3 (Table 4b).

The data also showed that for some talkers the first and second formant frequencies differed across days. For the first formant frequencies, a significant main effect was recorded for DAY for A1, C1, C2, and $\mathrm{C} 3$. The DAY effect depended on the word spoken as indicated by the interaction between DAY and WORD. Five words for A1 (Table 4c), two words for C1 (Table 4d), three words for C2 (Table 4d), and one word for C3 (Table 4d) showed significant post hoc differences between DAYs. The DAY effect also depended on the auditory feedback condition as indicated by the interaction between DAY and CONDITION for talkers $\mathrm{A} 1, \mathrm{C} 1$, and $\mathrm{C} 3$. This was recorded for two auditory feedback conditions for A1 (Table 4c), three conditions for C1 (Table 4d), and one condition for C3 (Table 4d).

For the second formant data, the results indicated a main effect for DAY for $A 1, A 2$, and $C 1$. In addition, there was a DAY by WORD effect for talkers A1, C1, and C3 which involved five words for A1 (Table 4c), two words for C1 (Table 4d), and one word for C3 (Table $4 \mathrm{~d}$ ). There was also a DAY by CONDITION effect for $\mathrm{A} 2$ and $\mathrm{C} 1$ which involved significant differences for one condition for each talker (Tables $4 \mathrm{c}$ and $4 \mathrm{~d}$ ).

The mean error results showed the amount of within-cell variance for the data (Table 3). For both 

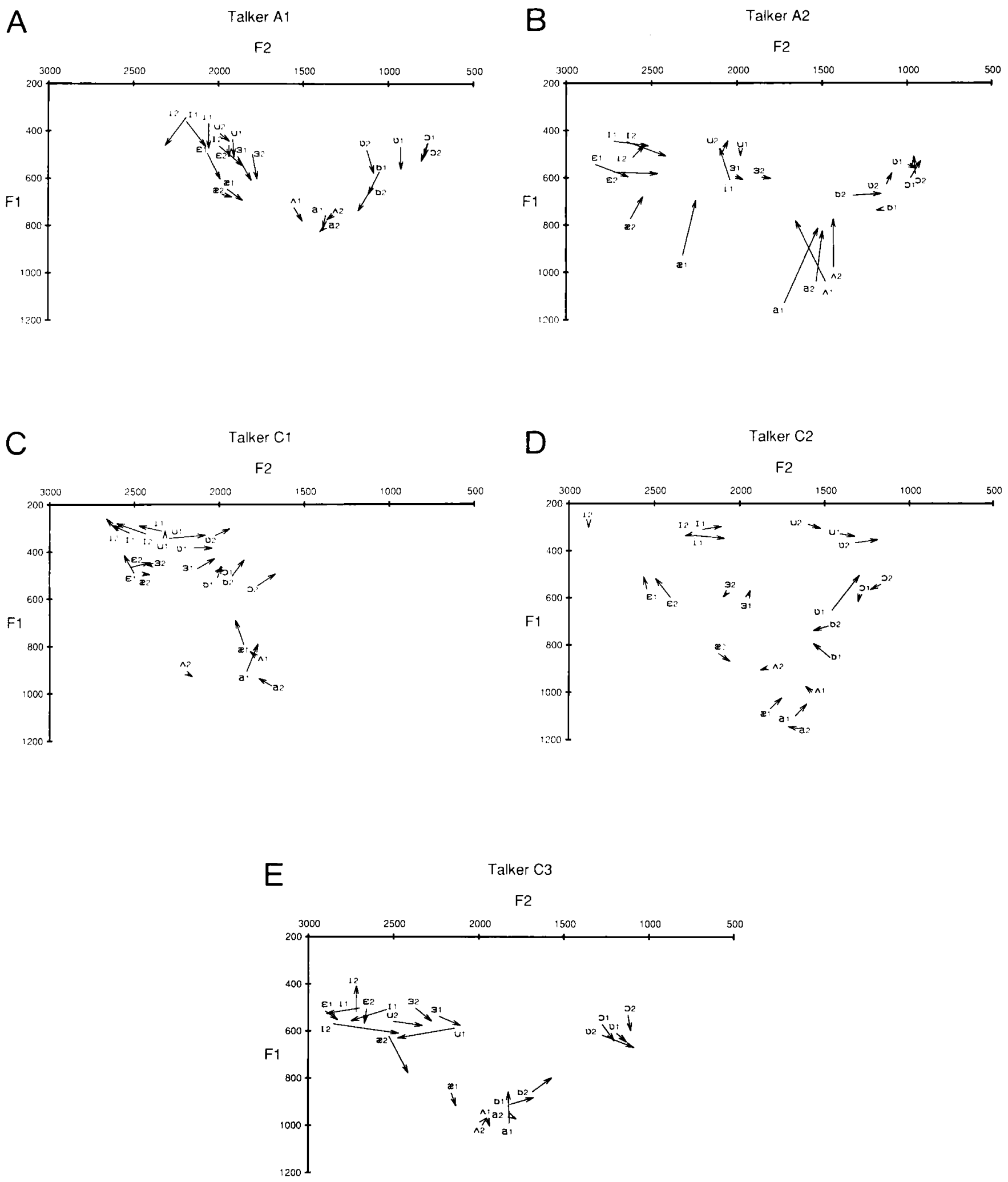

Figure 1. (a) Mean values for the first and second formant frequencies for the vowels spoken by $A 1$. The arrows indicate changes that occurred between the conditions ON and OFF1. (b) Mean values for the first and second formant frequencies for the vowels spoken by A2. The arrows indicate changes that occurred between the conditions ON and OFF1. (c) Mean values for the first and second formant frequencies for the vowels spoken by $\mathrm{C} 1$. The arrows indicate changes that occurred between the conditions ON1 and OFF. (d) Mean values for the first and second formant frequencies for the vowels spoken by $\mathrm{C} 2$. The arrows indicate changes that occurred between the ON1 and OFF conditions. (e) Mean first and second formant frequency values for the vowels spoken by C3. The arrows indicate changes that occurred between the ON1 and OFF conditions. 


\begin{tabular}{|c|c|c|c|c|c|c|c|c|}
\hline Talker & Day & Condition & Word & $\begin{array}{c}\text { Condition } \times \\
\text { Word }\end{array}$ & $\begin{array}{l}\text { Day } \times \\
\text { Word }\end{array}$ & $\begin{array}{c}\text { Day } \times \\
\text { Condition }\end{array}$ & $\begin{array}{c}\text { Day } \times \text { Cond } \\
\times \text { Word }\end{array}$ & $\begin{array}{c}\text { Mean Square } \\
\text { Error }\end{array}$ \\
\hline \multicolumn{9}{|c|}{ First Formant Data } \\
\hline A1 & $20.431^{\bullet}$ & $351.018^{*}$ & $343.690^{*}$ & $2.643^{*}$ & $2.696^{*}$ & $4.555^{*}$ & $1.579^{*}$ & 36.61 \\
\hline $\mathrm{A} 2$ & 0.055 & 4.021 & $231.528^{*}$ & 1.596 & 0.573 & 2.549 & $1.314^{*}$ & 71.31 \\
\hline $\mathrm{C} 1$ & $33.425^{*}$ & $33.913^{*}$ & $362.731^{\circ}$ & $2.335^{*}$ & $1.900^{*}$ & $5.300^{*}$ & $1.483^{\star}$ & 57.40 \\
\hline $\mathrm{C} 2$ & $10.084^{*}$ & 3.718 & $477.136^{*}$ & $1.976^{*}$ & $1.952^{*}$ & 3.019 & $1.183^{*}$ & 65.78 \\
\hline C3 & $5.807^{*}$ & $38.518^{*}$ & $194.257^{*}$ & $4.570^{*}$ & $1.827^{\star}$ & $6.261^{\bullet}$ & $1.365^{\star}$ & 67.34 \\
\hline \multicolumn{9}{|c|}{ Second Formant Data } \\
\hline A1 & $30.805^{\star}$ & 3.946 & $1006.143^{*}$ & $2.935^{\star}$ & $3.719^{*}$ & 1.115 & $1.153^{*}$ & 75.00 \\
\hline $\mathrm{A} 2$ & $21.182^{*}$ & $28.165^{\star}$ & $666.196^{\star}$ & $1.888^{*}$ & 1.373 & $7.889^{*}$ & $1.099^{*}$ & 145.91 \\
\hline $\mathrm{C} 1$ & $12.793^{\star}$ & 1.613 & $1+9.882^{*}$ & 1.412 & $2.346^{*}$ & $7.272^{*}$ & $1.497^{*}$ & 135.86 \\
\hline $\mathrm{C} 2$ & 0.155 & 0.631 & $265.696^{*}$ & $1.646^{\star}$ & 0.654 & 0.225 & $1.526^{*}$ & 149.69 \\
\hline C3 & 4.591 & 6.904 & $397.178^{*}$ & $3.518^{\star}$ & $2.148^{\star}$ & 1.633 & 0.989 & 148.06 \\
\hline
\end{tabular}

- indicates a significant effect $(p<0.01)$.

the first and second formant data, A1 showed the smallest within-cell variation. However, the withincell variation was approximately the same across the other four implant users. The amount of day-to-day variation is also indicated by the product of the mean error and the $F$ ratio for DAY. For the first formant data, A2 showed only a small amount of day-to-day variation while $\mathrm{C} 1$ showed the largest amount of day-to-day variation. For the second formant data, C2 showed only a small amount of day-to-day variation whereas A2 showed the largest

Table 4a. Results of post hoc analyses showing significant CONDITION effects for Talkers $A 1$ and $A 2$

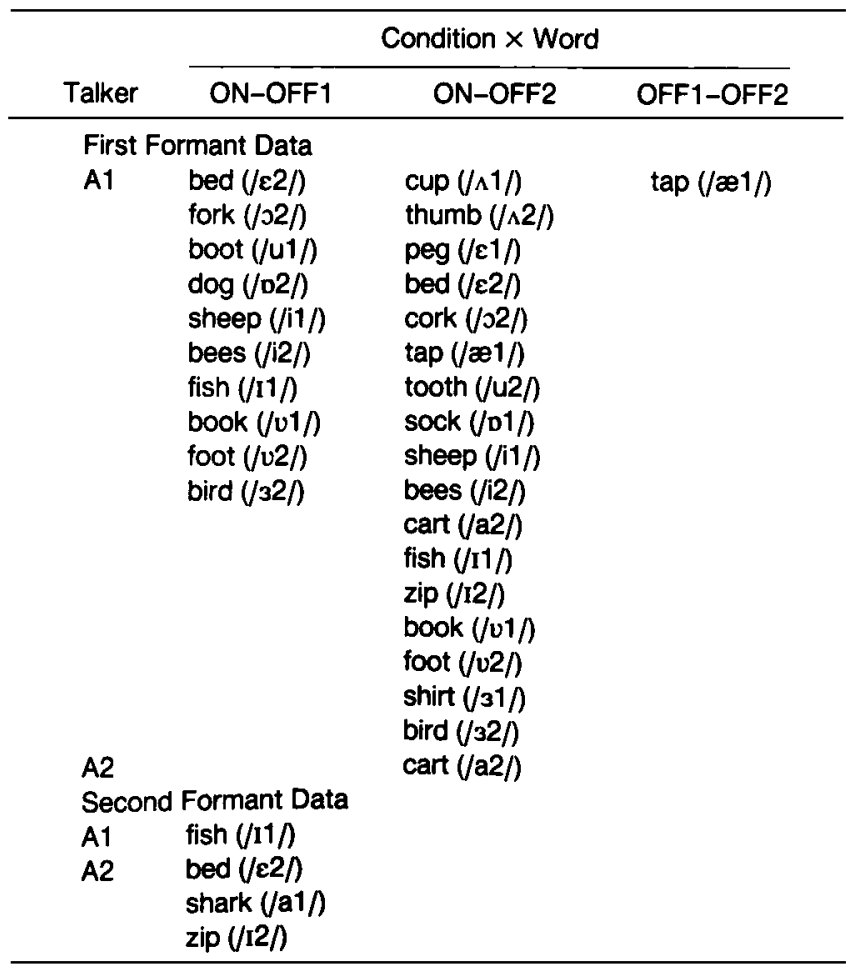

variation. The day-to-day variation for the second formant data for $\mathrm{C} 1$ was also quite large.

\section{Discussion}

The results of this study demonstrated. that the effect of auditory feedback from the Nucleus cochlear implant for vowel production was particular to the individual and depended on the data collection day and on the word being spoken.

In general, the changes in vowel production across different auditory feedback conditions were minimal. However, the condition effects that were observed in our data were of two types. First, the largest main CONDITION effect was observed for $\mathrm{A} 1$ for the first formant frequencies, because of an overall shift in the first formant values to higher levels when the processor was turned off. This effect was apparent in the OFF1 condition and remained when the processor stayed switched off for a longer period of time (OFF2). Significant post hoc differences were also observed for the first formant data for three of the other talkers. However, for these implant users,

Table 4b. Results of post hoc analyses showing significant CONDITION effects for Talkers C1, C2, and C3

\begin{tabular}{|c|c|c|c|}
\hline \multirow[b]{2}{*}{ Talker } & \multicolumn{3}{|c|}{ Condition $\times$ Word } \\
\hline & OFF-ON1 & OFF-ON2 & ON1-ON2 \\
\hline $\begin{array}{l}\text { First } \\
\text { C1 } \\
\text { C2 } \\
\text { C3 } \\
\\
\text { Secor } \\
\text { C2 } \\
\text { C3 }\end{array}$ & $\begin{array}{l}\text { rmant Data } \\
\text { book (/u1/) } \\
\text { van }(/ æ 2 /) \\
\text { sheep }(/ 11 /) \\
\text { shark (/a1/) } \\
\text { Formant Data } \\
\text { bees }(/ 2 / 2) \\
\text { peg }(/ \varepsilon 1 /) \\
\text { boot }(/ \mathrm{u} 1 /) \\
\text { zip }(/ \mathbf{1} 2 /)\end{array}$ & $\begin{array}{l}\text { shark (/a1/) } \\
\text { foot }(/ \mathrm{v} 2 /) \\
\operatorname{van}(/ æ 2 /) \\
\text { sheep }(/ 11 /)\end{array}$ & 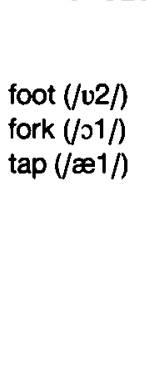 \\
\hline
\end{tabular}




\begin{tabular}{|c|c|c|c|c|c|c|}
\hline \multirow[b]{2}{*}{ Talker } & \multicolumn{3}{|c|}{ Day $\times$ Word } & \multicolumn{3}{|c|}{ Day $\times$ Condition } \\
\hline & Day 1-Day 2 & Day 1-Day 3 & Day 2-Day 3 & Day 1-Day 2 & Day 1-Day 3 & Day 2-Day 3 \\
\hline \multicolumn{7}{|c|}{ First Formant Data } \\
\hline A1 & & $\begin{array}{l}\operatorname{cup}(/ \wedge 1 /) \\
\text { tooth }(/ \mathrm{u} 2 /) \\
\text { cart }(/ \mathrm{a} 2 /)\end{array}$ & $\begin{array}{l}\text { tooth }(/ \mathrm{u} 1 /) \\
\text { sheep }(/ \mathrm{i} 1 /) \\
\text { cart }(/ \mathrm{a} 2 /) \\
\text { fish }(/ \mathrm{I} 1 /)\end{array}$ & & $\begin{array}{l}\text { ON } \\
\text { OFF1 }\end{array}$ & $\begin{array}{l}\text { ON } \\
\text { OFF1 }\end{array}$ \\
\hline \multicolumn{7}{|c|}{ Second Formant Data } \\
\hline$A 1$ & $\begin{array}{l}\text { boot }(/ \mathrm{u} 1 /) \\
\text { bees }(/ 12 /) \\
\text { fish }(/ 11 /) \\
\text { bird }(/ 32 /)\end{array}$ & $\begin{array}{l}\operatorname{boot}(/ \mathrm{u} 1 /) \\
\operatorname{dog}(/ \mathrm{p} 2 /) \\
\operatorname{fish}(/ \mathrm{l} 1 /)\end{array}$ & & s & & \\
\hline A2 & & & & & OFF2 & OFF2 \\
\hline
\end{tabular}

\begin{tabular}{|c|c|c|c|c|c|c|}
\hline \multirow[b]{2}{*}{ Talker } & \multicolumn{3}{|c|}{ Day $\times$ Word } & \multicolumn{3}{|c|}{ Day $\times$ Condition } \\
\hline & Day 1-Day 2 & Day 1-Day 3 & Day 2-Day 3 & Day 1-Day 2 & Day 1-Day 3 & Day 2-Day 3 \\
\hline \multicolumn{7}{|c|}{ First Formant Data } \\
\hline $\mathrm{C} 1$ & $\operatorname{sock}(/ \mathrm{p} 1 /)$ & bird $(/ 32 /)$ & & & $\begin{array}{l}\text { OFF } \\
\text { ON1 }\end{array}$ & $\begin{array}{l}\text { OFF } \\
\text { ON1 } \\
\text { ON2 }\end{array}$ \\
\hline $\mathrm{C} 2$ & $\begin{array}{l}\operatorname{van}(/ æ 2 /) \\
\operatorname{dog}(/ \mathrm{p} 2 /) \\
\text { book }(/ v 1 /)\end{array}$ & $\begin{array}{l}\operatorname{dog}(/ \mathrm{v} 2 /) \\
\text { book }(/ v 1 /)\end{array}$ & & & & \\
\hline C3 & thumb $(/ \wedge 2 /)$ & thumb $(/ \wedge 2 /)$ & & OFF & OFF & \\
\hline $\begin{array}{l}\text { Secon } \\
\text { C1 } \\
\text { C3 }\end{array}$ & $\begin{array}{l}\text { rmant Data } \\
\text { tooth (/u2/) } \\
\text { tooth (/u2/) }\end{array}$ & $\begin{array}{l}\text { shark (/a1/) } \\
\text { tooth (/u2/) }\end{array}$ & & ON1 & ON1 & \\
\hline
\end{tabular}

the effect did not occur in the same direction for all the words and in each case were significant for only a few words. Second, the WORD by CONDITION effects for the second formant frequency values suggested that for some vowels, as described below, these values tended to shift towards the center of the vowel quadrilateral when auditory feedback was withdrawn. Only one talker, A2, showed a CONDITION effect in the second formant values that was consistent across days. However, for two other talkers (A1 and C3), CONDITION by WORD effects were due to similar changes in the second formant values. For A1, significant changes occurred for the front vowel /I/ in the word "fish". This effect is shown in the first graph of Figure 2. For A2, significant changes occurred between the $\mathrm{ON}$ and OFF1 conditions for the two front vowels in the words "bed" and "zip" (Figure 2). Talker C3 showed similar effects to the adult speakers in terms of significant changes between conditions. This talker showed a tendency for the second formant frequencies of front vowels / $\varepsilon /$ and /I/ in the words "peg" and "zip" to be more neutralised when the processor was turned off (Figure 2). In all three cases the effect was apparent in the OFF1 or ON1 conditions. However, this effect was not present when the processor remained switched off (OFF2 for A1 and A2) or switched on (ON2 for $\mathrm{C} 3$ ) for longer periods of time.

In order to compare our findings with those from Svirsky and Tobey (1991), we need to consider their results in terms of consistency of the CONDITION effect across the ON/OFF sessions, the formant which shows the effect and the duration of the off period. In their data, a CONDITION effect was consistently recorded only for the second formant of three vowels $/ \varepsilon /, / 1 /$ and $/ o /$. As the vowel $/ o /$ is a diphthong in Australian English and was not tested in our study, the findings of our study are consistent with those from Svirsky and Tobey (1991). However, the effect was less pronounced for our study in terms of consistency across talkers and across consonant environment.

It is evident from Tables $4 a$ and $4 b$ that most of the changes across conditions occurred between the on versus off conditions rather than between the two on and off conditions (ON1-ON2 or OFF1-OFF2). This finding supports the suggestion that change 


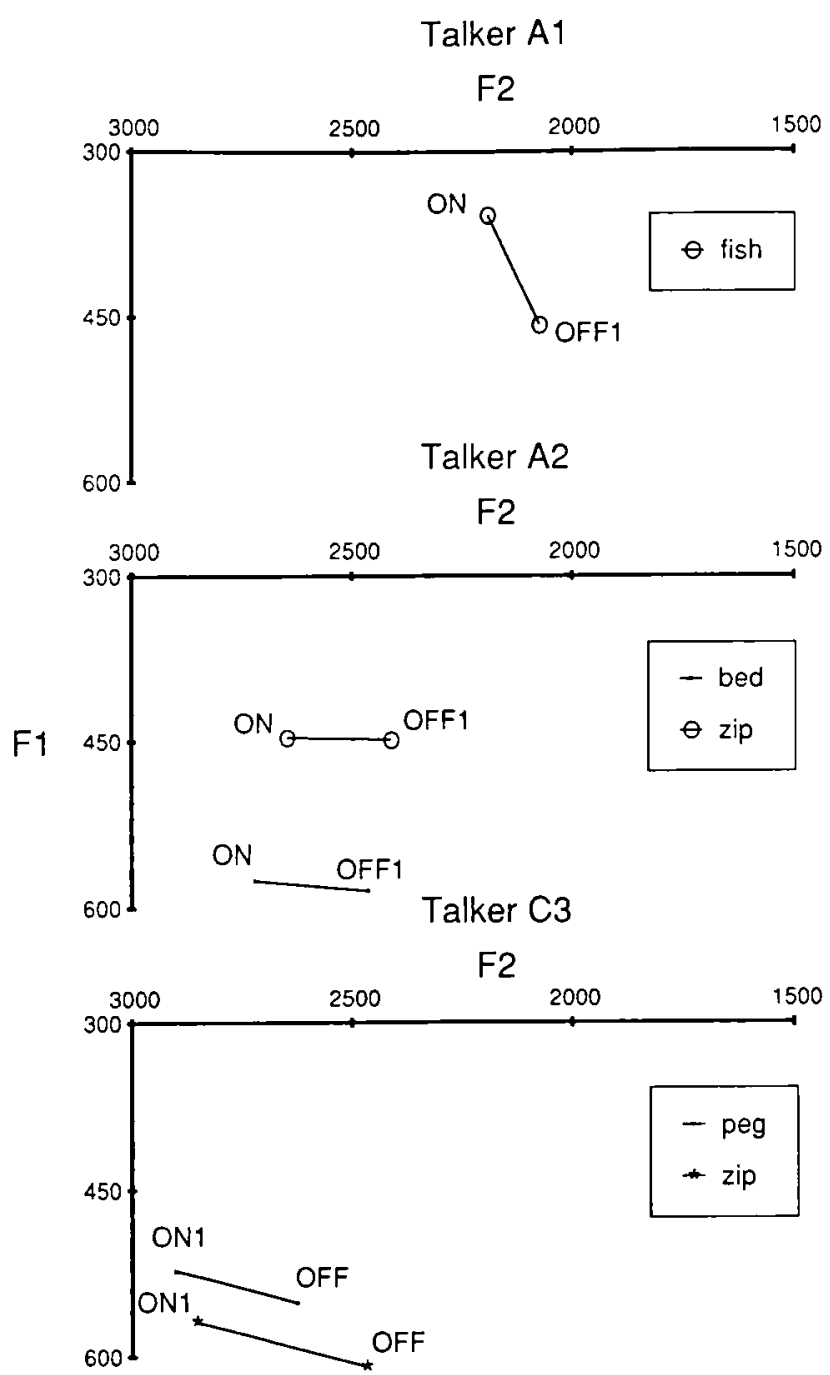

Figure 2. Mean values for the second formant frequencies of the vowels $/ \varepsilon /$ and $/ 1 /$. The first graph shows the changes that occurred between the conditions ON and OFF1 for the word "fish" spoken by A1. The second graph shows the changes that occurred between the conditions ON and OFF1 for the words "bed" and "zip" spoken by A2. The third graph shows the changes that occurred between the conditions OFF and ON1 for the words "peg" and "zip" spoken by C3.

across conditions reflect adjustments made to production because of auditory feedback and is consistent with the findings of Svirsky and Tobey (1991).

The data also showed that more changes occurred across the conditions for the postlinguistically deafened implant users than for the congenitally deafened implant user (Tables $4 \mathrm{a}$ and $4 \mathrm{~b}$ ). For $\mathrm{C} 1$, only one word showed significant change across conditions suggesting that this implant user may not use auditory feedback to monitor her speech production. This conclusion is also supported by the vowel space data (Figure 1c) which is more constricted in both the ON and OFF conditions. There are two implications of this result. First, there was less possibility

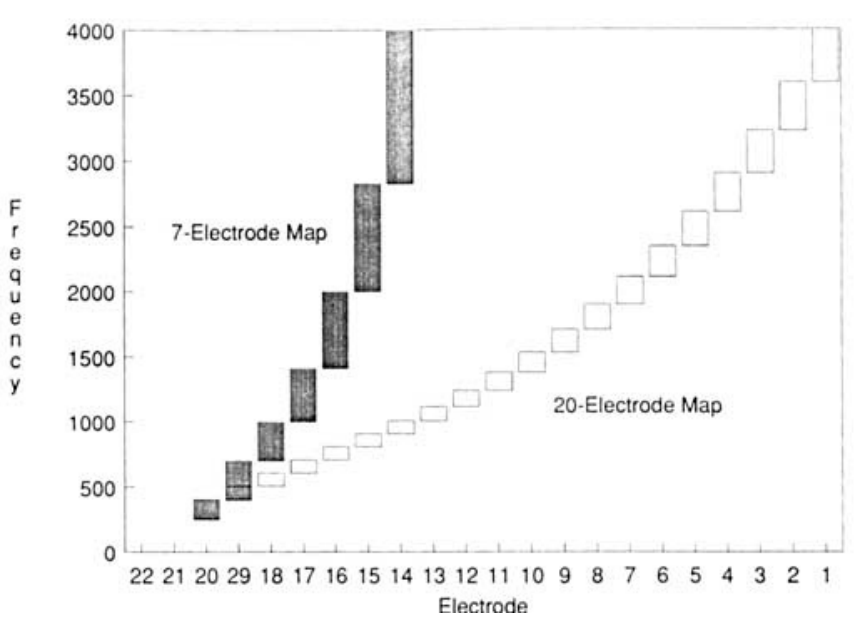

Figure 3. Frequency boundaries for 20 and 7 electrode maps.

of a more neutralised vowel space in the OFF condition. Second, it suggests that this patient has not incorporated auditory feedback into the long term monitoring of her speech production. Because of being a congenitally deafened person $\mathrm{C} 1$ had poorer perceptual skills than the other subjects, and her auditory experience before implantation was more limited.

Among the three postlinguistically deafened implant users, the results for $C 2$ differed from those of the other two implant users. Although our data showed some change across conditions for child C2, the data did not reveal a centralization effect for the vowels $/ \varepsilon /$ and $/ I /$. Talker C2 differed from the other subjects with respect to the number of electrodes available for stimulation and speech processing strategy. Thus, the speech signal received by this talker would be more restricted compared to the signal provided when the complete electrode array is available for stimulation. This is shown in Figure 3 , where the frequency boundaries for 20- and 7-electrode maps are given.

The post hoc analyses also highlighted the variation in the speech samples. DAY by CONDITION effects for four of the talkers indicated that the variation between conditions was more significant on some days than on others. There may be CONDITION by WORD effects for individual days which are masked in the overall analysis because we have considered the pooled variance across days. In terms of day-to-day variation, $\mathrm{C} 1$ showed large variation for both first and second formant data indicating that her speech production varied considerably across sessions. Within-cell variation was smallest for A1 (Table 3) indicating that this implant user was the most consistent talker within each session. This talker also showed the most change across conditions. This may be partly because the small mean error did not 


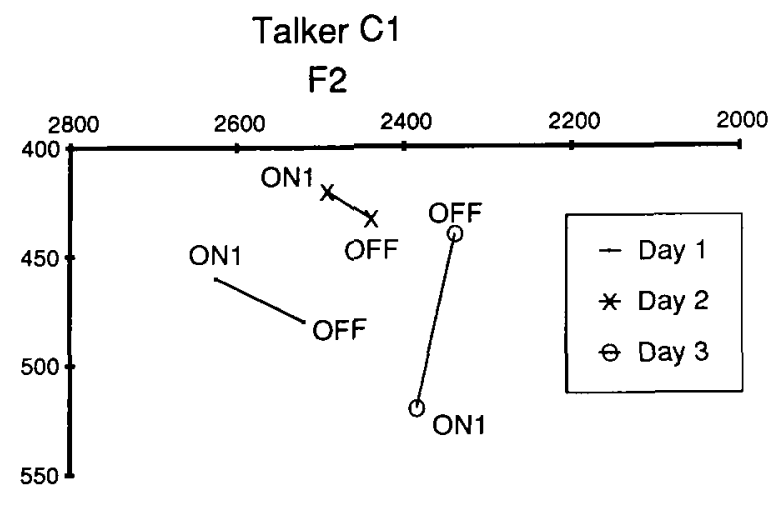

F1

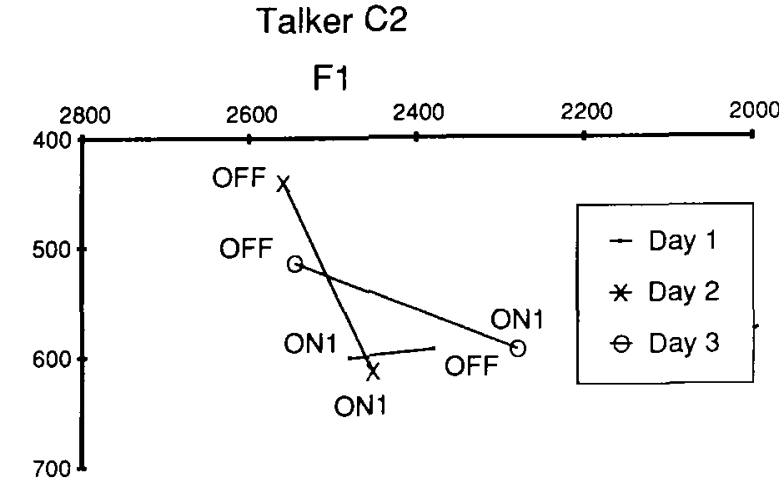

Figure 4. Mean values for the separate days for the formant frequencies of the vowel $/ \varepsilon /$. The two graph show the changes that occurred between the conditions OFF and ON1 for the word "bed" spoken by $\mathrm{C} 1$ and C2.

conceal the changes which occurred. For the four other implant users, within cell variation was approximately the same across talkers. Variation in the data may also explain the differing pattern of results for talkers $\mathrm{C} 1$ and $\mathrm{C} 2$. An examination of the data for these talkers revealed that where vowels were more neutralized in the OFF position, this effect was not consistent across days. An example, "bed" for $\mathrm{C} 1$ and $\mathrm{C} 2$, is shown in Figure 4.

There is no clear explanation for the less pronounced condition effect observed in our study. Given the spectral information transmitted by the speech processor and the implied relationship between speech perception and speech production, we might have expected to observe a shift in formant frequency values, which indicated the use of auditory feedback for talkers A1, A2, and C3. Experience can effect both perception and production. For instance, talker A1 has very good perceptual skills but his vowel space in the ON condition is more constricted than that for talkers A2, C2, and C3 (Figures 1a 1e). This decreases the margin for centralization to occur. Furthermore, for A1, A2, and C3, CONDITION effects for some but not all of the words containing the vowels $/ \varepsilon /$ and /I/ indicated that this effect was dependent on consonant environment. However, there was no systematic manipulation of the consonant environment in this study because of the need to use words which were in the vocabulary of the children. Therefore, further study is required to clarify. the effect of consonant environment. Another factor to consider is that the ON-OFF times for the adults were different from those of the children. In a recent study, Svirsky et al (1992) observed that changes in speech production were slower and less pronounced when the speech processor was turned off than when the speech processor was turned on after 24 hours of auditory deprivation. Thus, we may have observed a more pronounced effect for the adults if the conditions were reversed.

It is also unclear from our study why two front high and intermediate vowels, $/ \varepsilon /$ and $/ I /$ in particular, showed a significant condition effect. Svirsky and Tobey (1991) speculated that speakers may rely more on acoustic rather than orosensory cues for the production of these intermediate vowels. However, further study is required to examine why the two front high and intermediate vowels, in particular, show the greatest effect.

It is interesting to note that for talkers $\mathrm{A} 1$ and $\mathrm{A} 2$, shifts in the first formant frequency values between the ON and OFF1 conditions were in opposite directions. For talker A1, first formant frequency values were generally higher in the OFF1 condition. For talker A2, the first formant frequency values shifted lower when the processor was turned off. These changes may reflect shifts in fundamental frequency values when the processor is turned off. Further study is required to investigate the effect of altered auditory feedback conditions on fundamental frequency and the relationship between formant measures for cochlear implant users. It would also be useful to study changes in sound pressure levels in the absence of auditory feedback.

The results of our study suggest that some cochlear implant users may use auditory feedback to recalibrate their articulatory gestures. However, their use of auditory feedback may be influenced by such factors as etiology, speech processing strategy, baseline speech production, and consonant environment. Our study also demonstrated that it is difficult to separate changes due to auditory feedback from the day-to-day variability in speech production.

\section{Conclusions}

Our study found a less pronounced effect on the vowel production of cochlear implant users under conditions of altered auditory feedback than noted 
in previous studies. Although for three of the five talkers there was a condition effect for the first formant frequencies, this effect was only present across the majority of the words for one talker. Similarly for the second formant data, some talkers showed a marginal centralisation effect for the second formants of the vowels /I/ and $/ \varepsilon /$ in the absence of auditory feedback. Considerable day-to-day variability was also found for most of the talkers.

\section{References}

Angelocci AA, Kopp GA, and Holbrook A. The vowel formant frequencies of deaf and normal hearing eleven- to fourteen-yearold boys. J Speech Hear Dis 1964;29:156-170.

Busby PA, Tong YC, Roberts SA, Altidis PM, Dettman SJ, Blamey PJ, Clark GM, Watson RK, Dowell RC, and Rickards FW. Results for two children using a multiple-electrode intracochlear implant. J Acoust Soc Am 1989;86:2088-2102.

Clark GM, Blamey PJ, Busby PA, Dowell RC, Franz BK, Musgrave GN, Nienhuys TG, Pyman BC, Roberts SA, Tong YC, Webb RL, Kuzma JA, Money DK, Patrick JF, and Seligman PM. A multiple-electrode intracochlear implant for children. Arch Otolaryngol 1987;113:825-828.

Cowie R, and Douglas-Cowie E. Speech production in profound postlingual deafness. In Lutman, ME and Haggard MP, Eds. Hearing Science and Hearing Disorders. London: Academic Press, 1983:183-230.

Dowell RC, Whitford LA, Seligman PM, Franz BK-H, and Clark GM. Preliminary results with a minature speech processor for the 22-electrode Melbourne/Cochlear hearing prosthesis. In Sacristan T, Alvarez-Vincent JJ, Bartual J, Antoli-Candela F, et al., Eds. Proceedings of the XIV World Congress of Otorhinolaryngology, Head and Neck Surgery, Madrid, Spain, 1989. Amsterdam: Kugler and Ghedini Publications, 1990:1167-1173.

Economou A, Tartter VC, Chute PM, and Hellman SA. Speech changes following reimplantation from a single-channel to a multichannel cochlear implant. J Acoust Soc Am 1992;92:13101323.

Fourcin AJ, Rosen SM, Moore BC], Douek EE, Clarke GP, Dodson $\mathrm{H}$, and Bannister LH. External electrical stimulation of the cochlea: Clinical, psychological speech-perceptual and histological findings. Br J Audiol 1979;13:85-107.

Hudgins CV, and Numbers FC. An investigation of the intelligibility of the speech of the deaf. Genet Psychol Monogr 1942;25:289-392.

Kirk KI, and Hill-Brown C. Speech and language results in children with a cochlear implant. Ear Hear 1985;6:36S-47S.

Lane H, Perkell J, Svirsky M, and Webster J. Changes in speech breathing following cochlear implant in postlingually deafened adults. J Speech Hear Res 1991;34:526-533.

Lane $\mathrm{H}$, and Wozniak Webster $\mathrm{J}$. Speech deterioration in postlingually deafened adults. J Acoust Soc Am 1991;89:859-866. Leder SB, Spitzer JB, Milner P, Flevaris-Phillips C, Richardson F, and Kirchner JC. Reacquisition of contrastive stress in an adventitiously deaf speaker using a single channel cochlear implant. J Acoust Soc Am 1986;79:1967-1974.

Markides A. The speech of deaf and partially-hearing children with special reference to factors affecting intelligibility. $\mathrm{Br} J$ Commun Disord 1970;5:126-140.

Mc Garr NS, and Osberger MJ. Pitch deviancy and intelligibility of deaf speech. J Commun Disord 1978;11:237-247.

Monsen RB. Acoustic qualities of phonation in young hearingimpaired children. J Speech Hear Res 1979;22:270-288.
Osberger MJ, and Levitt $\mathrm{H}$. The effect of timing errors on the intelligibility of deaf children's speech. J Acoust Soc Am 1979;66:1316-1324.

Nober EH. Articulation of the deaf. Except Child 1967;33:611-621.

Oster AM. Some effects of cochlear implantation on speech production. Speech Transmission Laboratory (Stockholm): Quarterly Progress Report 1986;1:81-89.

Perkell J, Lane H, Svirsky M, and Webster J. Speech of cochlear implant patients: A longitudinal study of vowel production. J Acoust Soc Am 1992;91:2961-2978.

Peterson GE, and Lehiste I. Duration of syllable nuclei in English. J Acoust Soc Am 1960;32:693-703.

Plant G. The effects of a long-term hearing loss on speech production. Speech Transmission Laboratory (Stockholm): Quarterly Progress Report, 1983;1:18-35.

Plant G. A diagnostic speech test for severely and profoundly hearing-impaired children. Aust J Audiol 1984;6:1-9.

Plant $G$, and Hammarberg B. Acoustic and perceptual analysis of the speech of the deafened. Speech Transmission Laboratory (Stockholm): Quarterly Progress Report 1983;2-3:85-107.

Plant G, and Oster AM. The effects of cochlear implantation on speech production. A case study. Speech Transmission Laboratory (Stockholm): Quarterly Progress Report 1986;1:65-85.

Skinner MW, Holden LK, Holden TA, Dowell RC, Seligman PM, Brimacombe JA, and Beiter AL. Performance of postlinguistically deaf adults with the Wearable Speech Processor WSP II and Mini Speech Processor MSP of the Nucleus Multi-Electrode Cochlear Implant. Ear Hear 1991;12:3-22.

Smith CR. Residual hearing and speech production in deaf children. J Speech Hear Res 1975;18:795-811.

Svirsky MA, Lane H, Perkell JS, and Wozniak J. Effects of short term auditory deprivation on speech production in adult cochlear implant users. J Acoust Soc Am 1992;92:1284-1300.

Svirsky MA, and Tobey EA. Effect of different types of auditory stimulation on vowel formant frequencies in multichannel cochlear implant users. J Acoust Soc Am 1991;89:2895-2904.

Tartter V, Chute P, and Hellman S. The speech of a postlingually deafened teenager during the first year of use of a multichannel cochlear implant. J Acoust Soc Am 1989;86:2113-2122.

Tobey EA, Angelette S, Murchinson C, Nicosia J, Sprague S, Staller S], Brimacombe JA, and Beiter AL. Speech production performance in children with multichannel cochlear implants. Am J Otol 1991;12:165-173.

Tobey EA, and Hasenstab MS. Effects of a Nucleus multichannel cochlear implant upon speech production in children. Ear Hear 1991;12,4:48S-54S.

Waters T. Speech therapy with cochlear implant wearers. Br J Audiol 1986;20:35-43.

Zimmermann G, and Rettaliata P. Articulatory patterns of an adventitiously deaf speaker: Implications for the role of auditory information in speech production. J Speech Hear Res 1981;24:169178.

Acknowledgments: We would like to express our appreciation to the staff at St. Mary's School for Children with Impaired Hearing and the Cochlear Implant Clinic at the Royal Victorian Eye and Ear Hospital. We would like to thank the participants and their families for their cooperation. We would also like to thank Dr. Mary Joe Osberger, Dr. Nancy Tye-Murray and Dr. Mario Svirsky for their helpful comments on earlier drafts of this manuscript.

Address reprint requests to Ms. Louise M. Richardson, Department of Otolaryngology, 384-388 Albert Street, East Melbourne, 3002, Victoria, Australia.

Received August 21, 1992; accepted May 21, 1993. 


\section{University Library}

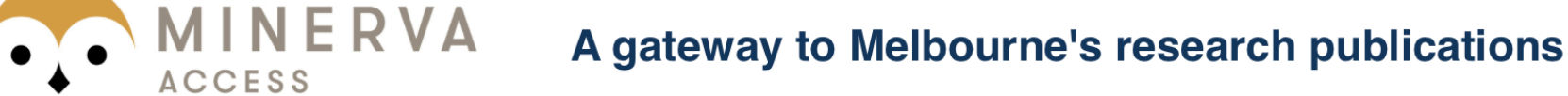

Minerva Access is the Institutional Repository of The University of Melbourne

\section{Author/s:}

Richardson, Louise M.;Busby, Peter A.;Blamey, Peter J.;Dowell, Richard C.;Clark, Graeme M.

Title:

The effects of auditory feedback from the nucleus cochlear implant on the vowel formant frequencies produced by children and adults

Date:

1993

Citation:

Richardson, L. M., Busby, P. A., Blamey, P. J., Dowell, R. C., \& Clark, G. M. (1993). The effects of auditory feedback from the nucleus cochlear implant on the vowel formant frequencies produced by children and adults. Ear and Hearing, 14(5), 339-349.

Persistent Link:

http://hdl.handle.net/11343/27342 